\title{
Intelectuales públicos judios en la Argentina, siglo XXI
}

David William Foster

Arizona State University

\section{RESUMEN}

La dictadura militar argentina de las décadas de 1970 y 1980 promovió la persecución de la comunidad judía. Desde 1983, nuevamente en democracia, muchos judíos argentinos participaron activamente en política y en debates culturales e intelectuales públicos. Las voces más notorias, que son analizadas en este artículo, fueron las de Ricardo Forster, Alejandro Horowicz y Horacio Verbitsky.

\section{PALABRAS CLAVE}

Antisemitismo, judíos, intelectual público, Argentina.

\section{ABSTRACT}

Argentina's military dictatorship of the 1970s and 1980s promoted the pursuit of the Jewish community. Since 1983, again in democracy, many Argentine Jews took actively part in politics and in cultural and public intellectuals' debates. The most notorious voices, which are analyzed in this article, were those of Ricardo Forster, Alejandro Horowicz and Horacio Verbitsky.

\section{KEYWORDS}

Anti-Semitism, Jews, public intellectual, Argentina. 
Me pregunto si [la contribución judía] ha sido diferente de la de otras colectividades. No lo sé. Tampoco puedo imaginar cómo medirla, cómo expresarla en datos contundentes e irrefutables.

No se me escapa que la pregunta es importante para quienes se preocupan por la construcción y reconstrucción permanente de la subjetividad comunitaria. También para aquellos que - sensibles a manifestaciones de hostilidad que por marginales no son menos dolorosas- se preocupan por mostrar lo aportad por la colectividad al acervo común y, sobre todo, su indeclinable compromiso con la comunidad nacional.

José Luis Romero en Levinsky 2005

Tras la persecución de los judíos durante la tiranía militar del periodo 1976-1983, la vida judía de Buenos Aires repuntó con el retorno a la democracia. Parte de este proceso involucró la participación activa y pública de judíos en los gobiernos democráticos y en los foros socioculturales que acompañaban y analizaban la redemocratización de la sociedad argentina.

Aunque habría mucho que decir en cuanto a una trayectoria histórica a partir de 1983, como la presencia de Marcos Aguinis (aunque transitoriamente), en el cargo de secretario de Cultura y luego director fundador del Programa Nacional para la Democratización de la Cultura (Prondec), o de la camada de judíos en el gobierno de Menem que estudia Diego Melamed (Los judíos y el menemismo), quisiera enfocarme en algunas figuras señeras del debate público que ejemplifican el papel como intelectuales públicos de los judíos. Por intelectual público entendemos no solamente una persona que publica libros, sino que, a través de sus libros y gracias a ellos, intervienen en los debates públicos, ya sea en los foros oficiales o en los medios masivos, y cuyos libros sirven como punto de partida para los debates públicos al provocar opiniones encontradas sobre los temas actuales ${ }^{1}$.

Me enfocaré en tres nombres de voces actuales: Ricardo Forster, Alejandro Horowicz y Horacio Verbitsky, entendiendo que hay muchos otros que entrarían en un estudio monográfico del tema².

1 Pienso, por ejemplo, en el tratado de Roderic A. Camp sobre intelectuales en México, un tipo de estudio que no creo que se haya hecho sobre la Argentina.

2 Este ensayo es, en cierta forma, una segunda parte del estudio que publiqué como «Intellectuals, queer culture, and post-military Argentina». Examino las contribuciones a los debates que, en la Argentina, dieron eventualmente con la aprobación del matrimonio igualitario (llamado también matrimonio gay) en julio de 2010. Los intelectuales judíos cuya obra se 
Sin duda alguna, el intelectual judío-argentino más prominente -o más controversial - en este momento es mi cuasi colombroño Ricardo Forster $^{3}$ (1957- ). Interesado en cuestiones éticas, Forster profundiza en la relación entre la tradición judía, su herencia histórico-filosófica, y los temas de la vida contemporánea. En ese sentido, se siente profundamente judío ${ }^{4}$ y está comprometido con lo que dicha herencia tiene para aportar al país y a la sociedad en que vive. De este modo, manifiesta la oposición a la asimilación sociocultural a una argentinidad laica, más allá de las diversas y contradictorias raíces étnicas de los orígenes de sus integrantes. Forster ejemplifica la supervivencia y la pervivencia de los estratos subyacentes de un sujeto social de la Argentina luego de 1983.

De particular importancia para el perfil público de Forster ha sido su participación de liderazgo en Carta Abierta, un grupo selecto de intelectuales que se formó en 2008 para apoyar a la presidenta Cristina Fernández de Kirchner, cuyo gobierno viene siendo acusado sistemáticamente de demagogia, por lo cual sus proyectos se estiman exentos de contenido crítico-intelectual. El propósito de Carta Abierta es dar algún tipo de legitimidad ideológica a los programas cristinistas, sin ser, como ellos mismos dicen, partidarios. Es importante notar, entonces, cómo Forster se exceptuó de Carta Abierta en cuanto al tema de una tercera presidencia para Fernández de Kirchner, por razones ético-legales que desdicen del impulso demagógico que contempla una reelección eterna. De todos modos, las misivas formales de Carta Abierta se proponen articular un foro de sostenido y acriteriado debate intelectual en el contexto de una cultura argentina $-\mathrm{y}$ de un periodismo nacional- profundamente partidarios, tendenciosos $y$, a veces, francamente difamadores respecto a todas las partes involucradas, comenzando por la misma jefa del Estado. En última instancia, la postura de Forster puede ser descrita como defensora de la necesidad de los debates sociopolíticos - como en textos claves recientes como La anomalía argentina (2010), La muerte del héroe (2011) y El litigio por la democracia (2011)—, a un nivel más

analiza incluyen a Viviana Gorbato, amén de no judíos como Néstor Perlongher y Juan José Sebreli (aunque este ha manifestado un interés particular en las vivencias judías en Buenos Aires, especialmente en su compilación La cuestión de los judíos en la Argentina, que se inserta en el turbulento panorama de la colectividad judía argentina de la década de 1960, tema que fuera estudiado sistemáticamente más recientemente por Leonardo Senkman. Remito también al arte público de Marcelo Brodsky y Santiago Porter, a quienes examino en «Two photographic interpretations of the bombing of the AMIA». Ver también mi texto «The jewish presence in Latin America» para obtener una lista exhaustiva acerca de los debates sobre la presencia sociohistórica de los judíos en Argentina.

3 Los dos nos llamamos originalmente Foerster (también se escribe Förster).

4 Una antigua apotegma antisemita preguntaría: ¿primero judío y, luego, argentino?... Supongo que Forster rechazaría rotundamente semejante incertidumbre retórica. Ver sus propuestas sobre su identidad y su compromiso nacional en «Ricardo Forster: el oficio de pensar». 
allá de la política del momento y para que las decisiones de gobierno no puedan ser tomadas tensadas en el oportunismo del poder.

Aunque el criterio de Carta Abierta insiste en que no es un grupo partidario, la verdad es que para muchos es fundamentalmente kirchernista/ cristinista, por la forma en que parece funcionar para dar distinción intelectual a un gobierno que, también para muchos, pareciera renuente a este. En contraste, aunque se ha negado a afiliarse a los intelectuales que se ocupan enérgicamente a resaltar el antiintelectualismo de Fernández de Kirchner y asesores, Alejandro Horowicz (1949) pretende mantener una escrupulosa independencia imparcial en sus comentarios radiofónicos y periodísticos sobre los temas del día (en este momento, principalmente desde el diario Tiempo Argentino). Con un doctorado en Ciencias Sociales por la Universidad de Buenos Aires, Horowitz aspira a aportar a los debates - por ejemplo, el acuciante tema de las Malvinas - un riguroso criterio de conocimiento histórico y social, a manera de esquivar el bulto del imperativo de partir de una postura ideológica que plazca o no a determinadas facciones de la lucha política en juego.

A este efecto, Horowicz se sostiene en la fundamentación documental y bibliográfica de su formación académica, donde la nota judaica está más en la seriedad del manejo de las fuentes que en una formación personal judía, como en el caso de Forster ${ }^{5}$. Sin embargo, es consciente de sus raíces judías y de cómo constituyen parte de su compromiso intelectual con la Argentina. En el contexto de una discusión personal sobre el cuadro sociohistórico que recoge Diego Melamed en Irse (2002), Horowicz se expresó con énfasis que no pretendía desandar los pasos de sus antecesores que llegaron a la Argentina de Polonia con una mano adelante y otra atrás, y que el imperativo de quedarse en el país y de seguir ocupándose de sus historia social era inamovible ${ }^{6}$. La idea de irse, especialmente por las razones económicas que propulsaron mucho del irse en los primeros años del siglo, era reconocer la derrota del gran proyecto argentino decimonónico de inmigrar $y$, más que nada, el fracaso de la vida que los antecesores habían hecho en la Argentina.

El aporte intelectual de Horowicz descansa en dos libros claves. El más conocido es el análisis del desarrollo y la permanencia del peronismo, Las cuatros fases del peronismo, editado originalmente en 1985, pero actualizado en 2005. Cuatro fases no se ocupa de las nuevas fórmulas del peronismo que llegan con Menem, Kirchner y Fernández de Kirchner, sino que

5 ¿Será por eso que Horowicz no figura en el arriba mencionado registro de Levinsky, Herencias de la inmigración judía en la Argentina?

6 Conversación personal, Buenos Aires, octubre de 2003. 
su intento es hacer comprender por qué a pesar de sus enormes vaivenes políticos, que incluyen posturas ideológicas de las más diversas, el peronismo sigue siendo fundamentalmente el gran modelo de gobernación para el país. En este como en sus escritos en general, la prosa de Horowicz se destaca por la sutileza de su expresión y por el afán de dejar de lado las explicaciones fáciles -los lugares comunes de conocimiento prevalente y callejero - para aportar evidencia contraria en una forma retóricamente sutil y, muchas veces, de marcado tono irónico: «no se trata de lo que se alega», «no que se piensa/e», «lo que se cree, sino que es todo lo contrario», «en realidad, nada menos que», y «para entenderlo bien conviene, respetando rigurosamente los hechos, formular algunas precisiones». De esta manera, Horowicz formula un balance entre la sabiduría convencional y las alternativas que la auscultación de las fuentes y la debida contextualización de los acontecimientos pueden arrojar. Yo no estoy en condiciones de ponerle nota al proyecto de Horowicz y me conformo con ampararme en la alta calidad discursiva del texto para alegar que es uno de los ensayos imprescindibles sobre el peronismo.

Horowicz publicó en 2012 la que fuera su disertación doctoral, Las dictaduras argentinas: historia de una frustración nacional. En la medida en que las fuerzas armadas argentinas se erigían en la mayor oposición al peronismo, este estudio, que evidencia las mismas características de rigor documental y sutileza discursiva de Cuatro fases, constituye la otra cara de la moneda de la historia social argentina: las distintas encarnaciones de la dictadura (y no simplemente variantes de un solo proyecto autoritarioneofascista) en aras de imponer alternativas políticas - o apolíticas, en su pretendida formulación legitimizante - a los vaivenes políticos del país. Aunque los golpes de Estado no se dieron exclusivamente en el contexto del peronismo (de hecho, el peronismo vino como una respuesta a la tiranía militar desde el seno de los gobiernos de facto de las décadas de 1930 y 1940), es indudable que la dinámica privilegiada aquí es la de la cultura peronista versus la cultura castrense y el involucramiento de ambas partes a todos los aspectos pertinentes de la vida nacional y sus relaciones internacionales. Si el judaísmo informa la óptica de Horowicz sobre todo este inmenso panorama patrio, es por su afán de estar en la vereda de enfrente, evitando la tentación de repetir las consignas que justifican una y otra banda, de ser, como él mismo dice en la dedicatoria de Las dictaduras, «compinche en lo políticamente incorrecto».

Quisiera cerrar esta exposición refiriéndome a una de las voces judeoargentinas más controversiales del país. Dejo para otro momento el asesoramiento del discurso público de Horacio Verbitsky (1942) referente a sus vínculos con los programas del gobierno de Cristina Fernández de 
Kirchner. Baste enfatizar que Verbitsky ha sido uno de los más enérgicos soportes de la política del gobierno. Verbitsky tiene raíces muy problemáticas en la militancia montonera. Era compañero del legendario Rodolfo Walsh en la rama de inteligencia y propaganda del grupo y se alega que, a pesar de su propia negativa, tiene varias muertes de operativos guerrilleros en su haber, aunque se salvó de la muerte a manos de las fuerzas armadas que le tocó a Walsh. Verbitsky, hijo del afamado novelista social realista Bernardo Verbitsky, terminó perfilándose como uno de los más empeñados periodistas investigativos de la Argentina, y se ganó el sobrenombre de El Perro por la tenacidad de sus embates contra el abanico de mentiras y corrupciones que sostienen el proceso ejecutivo del poder a todos niveles. El escritor argentino Enrique Medina dijo en una de sus novelas referentes a la época menemista ${ }^{7}$ que la corrupción es un atractivo turístico en la Argentina y los mejores esfuerzos de Verbitsky se han afanado en darle la verdad documental y concreta a toda la extensión implícita de la afirmación de Medina.

Dos textos, entre una extensa bibliografía de obras que se han vendido muy bien en el mercado nacional e internacional, se destacan como ejemplos del trabajo de Verbitsky, que no deja títere con cabeza. El vuelo (1995) parte de denuncias hechas a Verbitsky por oficiales involucrados en los abusos humanos practicados en la Escuela Superior de la Mecánica de la Armada (ESMA) durante la llamada Guerra Sucia (1976-1983), para levantar un detallado panorama de una de las peores caras de la dictadura militar, que los intereses militares y de los sectores que los apoyaban han querido negar, minimizar, exonerar y callar. El vuelo fue bestseller y precisamente por documentar muchos detalles que antes eran solo conocidos en forma anecdótica. Verbitsky se fundamenta en las declaraciones informales y jurídicas de las víctimas, declaraciones que los mismos intereses anteriormente referidos quisieron impugnar, y así contribuyó a mantener vivo el debate nacional sobre la tiranía y, no sería exagerado decir, contribuyó a que se abrogase en 2005 la ley de Punto Final que se dictara en 1985 como medida para suspender definitivamente las investigaciones sobre los abusos humanos y el fenómeno de los desaparecidos durante dicha tiranía. El libro de Verbitsky fue solamente uno de los múltiples frentes de ataque al Punto Final, pero es en particular pertinente aquí por el acrecentado número, desproporcional en términos demográficos, de los judíos afectados por la represión ${ }^{8}$.

7 «Y esto no es poco en un país donde la corrupción es atractivo turístico». Medina 1998: 164.

8 El vuelo se tradujo al inglés en 1996 como The Flight. Confessions of an Argentine Dirty Warrior. 
Verbitsky publicó en 1991 Robo para la corona. Los frutos prohibidos del árbol de la corrupción, sobre el alto nivel de irregularidades, hasta para la Argentina, que se pudieron rastrear en el gobierno de Carlos Saúl Menem durante la primera década de este siglo, periodo caracterizado por los esfuerzos del menemismo de crear la ilusión de irrevocable prosperidad en el país bajo el lema de «Argentina es primer mundo». El título del libro dice tener su origen en la aseveración de uno de los mayores agentes de la corrupción, no se sabe si fue como un sello de orgullo por su dedicación o una forma de exculparse personalmente, pues ejercía sus funciones para un supuesto bien superior. Probablemente fue una combinación de las dos. El hecho es que el informe de Verbitsky tuvo una enorme repercusión en el gobierno de Menem, con el relevo de mucho personal, aunque sin, como suele ser el caso en la Argentina, poca resonancia en términos de consecuencias legales y penales. Dejo para una reflexión en otro momento el tema insinuado aquí: la Argentina produce un periodismo de investigación de excepcional calidad profesional y frutos informativos, pero casi nunca redunda en el procesamiento jurídico de los acusados.

Últimamente Verbitsky estuvo involucrado en el debate sobre la designación de Jorge Mario Bergoglio como Papa en marzo de 2014. Verbitsky publicó en $2005 \mathrm{El}$ silencio. De Paulo VI a Bergoglio. Las relaciones secretas de la Iglesia con la ESMA. Como databa de ocho años antes de la elevación de Bergoglio al papado, El secreto no pudo tomar en cuenta dicha elevación y se ciñe a la importancia de Bergoglio como arzobispo de Buenos Aires y jefe titular de la Iglesia católica en la Argentina. Es aquí donde se ve la hilacha de la postura controversial y, se podría decir, tendenciosa del periodismo de Verbitsky, pues los gobiernos de Kirchner y de Fernández de Kirchner han tenido intereses políticos en mantener abierta la discusión de la violación de derechos humanos durante la dictadura militar. De hecho, la arrogación de la Ley de Punto Final, como ya se dijo, es de 2005, y la ESMA, aunque un museo muy legítimo que da un testimonio elocuente sobre el tema, es también un espacio de propaganda sin ambages de dichos gobiernos. Los dos presidentes tuvieron serios enfrentamientos con Bergoglio por razones de sus políticas ícono, como la Ley de Matrimonio Igualitario, dictado en 2010 con el intransigente apoyo cristinista. Bajarle la cresta a Bergoglio estaba en el orden del día y su nombramiento como Papa parecía proporcionar una eximia oportunidad para desacreditarlo. De pronto abundaban las referencias a El silencio y se invitó a Verbitsky, junto con Martín Caparrós, a escribir una columna de op-ed para el New York Times sobre el nuevo Papa'. No sé si Verbitsky terminó entregando la

9 Comunicación telefónica personal con Sewell Chan, de la página op-ed del New York Times desde San Martín de los Andes (14 de marzo de 2013). 
suya (la de Caparrós, muy equilibrada - y hasta en forma jocosa- salió el 14 de marzo de 2013), pero la de Verbitsky nunca apareció, aunque sus pareceres sobre Bergoglio fueron muy citados en otras fuentes en inglés. La razón es fácil de deducir: el gobierno de Fernández de Kirchner se dio cuenta de que ya no había forma de poder contra Bergoglio, a quien acusara públicamente de querer revigorizar la Inquisición (Caparrós) y que más valía expropiarlo como símbolo nacional (de pronto Buenos Aires apareció, de la noche a la mañana del 16 al 17 de marzo, empapelado con afiches con la imagen del nuevo Papa que decían «argentino y peronista») y de besarle la mano como correspondía (cosa que se vio en cadena nacional el 17 de marzo). Cuando el Premio Nobel Adolfo Pérez Esquivel afirmó públicamente que Bergoglio no había tenido nada que ver con la guerra sucia de los militares y cuando hizo eco de esta afirmación Graciela Fernández Menjide, exintegrante de la Comisión Nacional sobre la Desaparición de Personas (Conadep) que produjo el informe Nunca más, ya parecía que las denuncias de Verbitsky tuvieron que hacer mutis por el foro.

El tema de El silencio señala cómo, si ya no hay censura en la Argentina, hay momentos cuando ciertos pareceres son más propicios que otros. Verbitsky se sentirá más allá de poder ser «congelado» (es decir, no ver publicado cierto texto entregado a un foro periodístico), pero la mostaza de la política argentina anda tan subida que es mejor recapacitar.

La forma en que Verbitsky ha venido interviniendo en los más agudos debates en la Argentina indica el vigor de su discurso periodístico y su perfil como intelectual público ${ }^{10}$. Indica también cómo el antisemitismo en la Argentina ya no es más que un fósil arqueológico y que las balas del tiroteo crítico ya no llevan marcas étnicas. No creo que nadie creyera que lo reportado por Verbitsky sobre Bergoglio y la dictadura tuviese que ver con la oportunidad de un judío de cobrar una revancha contra una Iglesia cuyo antisemitismo había sido, otrora, francamente de terror. Las aguas siguen bajando turbias en la política nacional y el estruendo es a veces aterradoramente ensordecedor. Pero ya en pleno siglo XXI, las voces judías, a diferencia de las épocas en que fueron confinadas a la prensa judía, ocupan un lugar que ya no es ni lejanamente marginal. 


\section{REFERENCIAS BIBLIOGRÁFICAS}

CAMP, Roderic A. (1985). Intellectualls and the State in Twentieth-century Mexico. Austin: University of Texas Press.

CAPARRÓS, Martín (2013, 13 de marzo). «God is an Argentine». Consultado el 22 de marzo de 2013 de http://www.nytimes.com/2013/03/15/opinion/god-is-an-argentine.html?_r=0

FORSTER, Ricardo (2010). La anomalía argentina. Buenos Aires: Editorial Sudamericana.

Ariel.

(2011). La muerte del héroe. Buenos Aires: Editorial

rial Planeta.

(2011). El litigio por la democracia. Buenos Aires: Edito-

FOSTER, David William (2008). «Intellectuals, queer culture, and post-military Argentina». En Luis Martin-Estudillo y Roberto Ampuero (editores). Post-Authoritarian Cultures; Spain and Latin America's Southern Cone. Nashville: Vanderbilt University Press.

(2012). «The jewish presence in Latin America». En Ben Vinson (editor). Oxford Bibliographies in Latin American Studies. Nueva York: Oxford University Press.

(2011). «Two photographic interpretations of the bombing of the AMIA». Consultado el 21 de abril de 2012 http://www. lehman.cuny.edu/ciberletras/v25/foster.htm

HOROWICZ, Alejandro (2005). Los cuatro peronismos. Buenos Aires: Edhasa.

tración nacional. Buenos Aires: Edhasa.

(2012). Las dictaduras argentinas: historia de una frus-

LEVINSKY, Roxana (2005). Herencias de la inmigración judía en la Argentina. Cincuenta figuras de la creación intelectual. Buenos Aires: Prometeo Editorial.

(2005). «Horacio Verbitsky: un periodismo comprometido». En Roxana Levinsky. Herencias de la inmigración judía en la Argentina. Cincuenta figuras de la creación intelectual. Buenos Aires: Prometeo Editorial.

(2005). «Ricardo Forster: el oficio de pensar». En Roxana Levinsky. Herencias de la inmigración judía en la Argentina. Cincuenta figuras de la creación intelectual. Buenos Aires: Prometeo Editorial.

MEDINA, Enrique (1998). El escritor, el amor y la muerte. Buenos Aires: Editorial Planeta. 
MELAMED, Diego (2002). Irse. Cómo y por qué los argentinos se están yendo del país. Buenos Aires: Editorial Sudamericana.

(2000). Los judíos y el menemismo. Un reflejo de la sociedad argentina. Buenos Aires: Editorial Sudamericana.

SEBRELI, Juan José (1968). La cuestión de los judíos en la Argentina. Buenos Aires: Editorial Tiempo Contemporáneo.

SENKMAN, Leonardo (1986). El antisemitismo en la Argentina. Buenos Aires: Centro Editor de América Latina.

VERBITSKY, Horacio (1996). The Flight: Confessions of an Argentine Dirty Warrior. Nueva York: The New Press.

(1991). Robo para la corona. Los frutos prohibidos del árbol de la corrupción. Buenos Aires: Editorial Planeta.

(2005). El silencio. De Paulo VI a Bergoglio. Las relaciones secretas de la Iglesia con la ESMA. Buenos Aires: Editorial Sudamericana. (1995). El vuelo. Buenos Aires: Editorial Planeta. 